\title{
Detecting Criminal Intent with the Concealed Information Test
}

\author{
Ewout H. Meijer*, Bruno Verschuere and Harald Merckelbach
}

Faculty of Psychology and Neuroscience, Department of Clinical Psychological Science, Maastricht University, P.O. Box 616, 6200 MD Maastricht, The Netherlands

\begin{abstract}
Lie detection procedures are typically aimed at determining whether a suspect is lying about a crime committed in the past. Recent threats of terrorism, however, have shifted attention away from solving old cases to preventing future crimes. In the experiment reported in this paper, we investigate whether a specific lie detection test, the Concealed Information Test, can be used to detect criminal intent. To investigate this issue, we randomly assigned 64 participants to either an informed innocent, an intent or a guilty condition. Participants in the guilty condition actually performed a mock crime whereas participants in the intent condition were stopped when they approached the location where the mock crime was to take place. The results show no difference in detection between the guilty and the intent condition, indicating that a CIT procedure can indeed be used to detect intent. This suggests that the CIT can be used within the recent legal framework that requires procedures allowing for the detection of criminal intent.
\end{abstract}

Keywords: Lie detection, guilty knowledge test, concealed information test, malintent, terrorism.

\section{INTRODUCTION}

Lie detection procedures are typically aimed at determining whether a suspect is lying about his or her involvement in an illegal act that has been committed days, months or even years ago. But recent threats of terrorism have shifted attention away from solving old cases to preventing future crimes. Recent laws consider the mere preparation of an act a criminal offence. The terrorism act 2006 (c.11), enforced in the United Kingdom, for example, makes engaging in any conduct in preparation for an intended act of terrorism punishable by life imprisonment. As a consequence, procedures that allow for the detection of criminal intentions are required. In the experiment reported in this paper, we investigate whether a specific lie detection test, the Concealed Information Test, can be used to detect criminal intent.

The Concealed Information Test (CIT; also known as the Guilty Knowledge Test; Lykken, 1959, 1998), aims to detect the presence or absence of crime-related information in a suspect's memory. In a typical CIT, the suspect is presented with a series of questions that concern crime details known to the police and the perpetrator, but not to an innocent suspect. With each question, several answer options are presented, including the correct one, a well as several plausible but incorrect options (e.g., 'Was the victim killed with a ... (a) gun, (b) knife, (c) rope, (d) bat, (e) screw driver'). Meanwhile, physiological parameters such as skin conductance are recorded. For innocent suspects, all options are equally plausible and will elicit similar physiological responses. However, for a guilty suspect, the correct option is salient and will elicit an enhanced response. Thus,

*Address correspondence to this author at the Faculty of Psychology and Neuroscience, Department of Clinical Psychological Science, Maastricht University, P.O. Box 616, 6200 MD Maastricht, The Netherlands; Tel: +31433884505, +31 43388 2222; Fax: +31433884196;

E-mail: eh.meijer@maastrichtuniversity.nl consistent stronger physiological responding to the correct answer options indicates knowledge of intimate crime details, from which involvement in the crime can be inferred. The CIT has good validity (Ben-Shakhar \& Elaad, 2003), and is widely employed as a forensic tool in Japan (Hira, 2002; Nakayama, 2002).

The theoretical basis of the CIT is provided by research on the human orienting reflex (Verschuere, Crombez, De Clercq, \& Koster, 2004). The orienting response entails a complex of reactions evoked by a novel stimulus or a change in stimulation (Sokolov, 1963). These reactions include an increase in skin conductance, decrease in heart rate, and suppression of respiration (Lynn, 1966). Importantly, orienting responses are also evoked by familiar stimuli that are significant to individuals, such as their own name. In a CIT, the correct alternative will have special significance for suspects who were actually involved in the crime, and evoke enhanced orienting responses.

Because the CIT aims to detect the presence or absence of pertinent information in long term memory, we have also referred to it as memory detection (Merckelbach \& Meijer, 2004; see also Meegan, 2008). Typically, the CIT addresses the issue whether a suspect possesses information about a crime that has been committed. Would it be possible to employ this technique to detect criminal intent, i.e., in those who plan a criminal act? Theoretically, there are at least two reasons why the CIT's efficiency to detect such intentions may be impaired compared to its efficiency to detect involvement in past actions. These have to do with memory and significance. First, an event that has been experienced allows for richer encoding and more elaboration. Therefore, details of crimes that have been committed may be remembered better than intentions consisting of vague scripts for prospective acts. Second, even when such scripts are remembered, their significance may be low. Research on informed innocents and the CIT supports this line of reasoning. In this research, subjects are typically assigned to 
one of three groups. The first consists of uninformed innocent subjects who are not involved in the mock crime and know nothing about it. The second consists of guilty subjects who are instructed to commit a mock crime. The third group consists of informed innocent subjects who are not actually involved in the crime, but are informed about the details of the crime. It has been repeatedly shown that memory of pertinent crime details can be detected in these informed innocent subjects, but to a lesser extent than in guilty subjects (Ben-Shakhar, 1999; Bradley, 1996). With this in mind, it is possible that CIT detection efficiency for intended actions will be lower than that for past actions, rendering the CIT as a suboptimal forensic tool to detect them. To investigate this issue, we assigned participants to an informed innocent, an intent or a guilt condition and compared CIT detection efficiency.

\section{MATERIALS AND METHODOLOGY}

\section{Participants}

Participants were 64 undergraduate students $(18 \mathrm{men})$ at Maastricht University (mean age 21.36 years; $\mathrm{SD}=2.28$, range 19 - 27). They read and signed an informed consent, and received course credits for their participation. The experiment was approved by the ethical committee of the Faculty of Psychology and Neuroscience.

\section{Procedure}

After signing the informed consent, participants were randomly assigned to one of three conditions: informed $(\mathrm{n}=$ $21)$, intent $(n=22)$ or guilty $(n=21)$. All participants were shown a PowerPoint presentation containing the pictures that later served as relevant items in the CIT. For those assigned to the intent or the guilty condition, the PowerPoint contained instructions to commit a mock crime. They were instructed to go to the third floor of the University building to retrieve keys from the chest pocket of a humanlike doll. With one of these keys they could open Franck Gelder's room located on the second floor. Upon entering this room they had to cover a security camera with a newspaper and search for a yellow safe located in a yellowish shutter cabinet underneath a desk. They then had to open the safe and steal the watch that was inside. Participants in the informed condition were told that their help was needed in a police investigation. They received a similar presentation, with the only difference that the textual information was phrased differently (e.g., 'the thief gained access to Franck Gelders' room on the second floor' versus 'go to Franck Gelders' room on the second floor'). The guilty group performed the mock crime as described. The intent group was treated the same as the guilty group until they approached the doll. They were then stopped and escorted back to the laboratory. All three groups were then subjected to a CIT.

The CIT consisted of one example question and 6 genuine questions. Each question was followed by a set of 6 answer options, among which was the correct answer. The first option was never the correct option and served to absorb novelty orienting responses. Questions presented during the CIT referred to (1) the object stolen from the safe; (2) The type of safe; (3) The object used to cover the security camera; (4) The location of the doll; (5) The type of cabinet the safe was placed in and (6) The name that was on the door of the room. Answers options consisted of pictorial stimuli. Each answer option was presented for 8 seconds, with an inter stimulus interval of 20 seconds. Participants had to respond to the presentation of each option with a verbal "no" answer. A participant-terminated break was given after completion of each question. To assess memory for the crime details, participants were given a recognition test after completion of the CIT. They were presented with all pictorial stimuli used in the CIT and asked to check the correct alternative to each question.

Questions and answer alternatives were presented on a 17 inch monitor, and all testing took place in a dimly lit, soundproof, air-conditioned laboratory. Participants were monitored from a control room by means of a video surveillance camera and a microphone.

\section{Physiological Measures}

Skin conductance was measured using a 24 bit DC 0.5 Volt system. Two Beckmann silver/silver chloride $(\mathrm{Ag} / \mathrm{AgCl})$ electrodes $(8 \mathrm{~mm}$ in diameter) were placed on the medial phalanges of the first and second fingers of the participants' non-dominant hand. Electrodes were filled with isotonic electrode paste $(0.9 \% \mathrm{NaCl})$. Data was acquired using Contact Precision Instruments bioamplifiers with a sample rate of $60 \mathrm{~Hz}$.

\section{Response Scoring and Data Analysis}

The maximal positive deflection in skin conductance during the $1 \mathrm{~s}$ to $5 \mathrm{~s}$ interval after stimulus onset was defined as the SCR. To eliminate individual differences in responsivity, within question standardized scores were computed by subtracting the mean of all 5 responses from the response to the critical item and dividing that by the standard deviation of all 5 responses (Ben-Shakhar, 1985). These standardized scores were then averaged over questions in order to produce a single detection score for the CIT. Additionally, data for 21 innocent participants were simulated using the procedure described by Meijer, Smulders, Johnston, and Merckelbach (2007).

\section{RESULTS}

Mean proportion correct recall as assessed with the memory check was $1.00(S D=0.00)$ in the guilty condition, $.99(S D=0.04)$ in the intent condition and $.92(S D=0.17)$ in the informed condition. A oneway ANOVA performed on these proportions revealed a significant effect $(F(2,61)=$ $4.00, p=.02)$. Post hoc comparisons revealed that correct recall was significantly worse in the informed condition than the intent condition $(p=.02)$ and the guilty condition $(p=$ 0.1 ), with no difference between the intent and the guilty condition.

Fig. (1) shows the mean standardized skin conductance responses for the four conditions (including the simulated innocent condition). A oneway ANOVA on these scores revealed a significant effect $(F(3,83)=9.7, p<.001)$. The results of the post hoc comparisons are given in Table 1. These tests revealed that all three conditions differed from the innocent group, while none of the conditions differ from each other. However, the difference between the informed and guilty condition approached significance $(p=.054)$. 
Furthermore, an ANOVA including only the three experimental conditions yielded a borderline significant linear trend $(F(1,61)=3.3, p=.08)$.

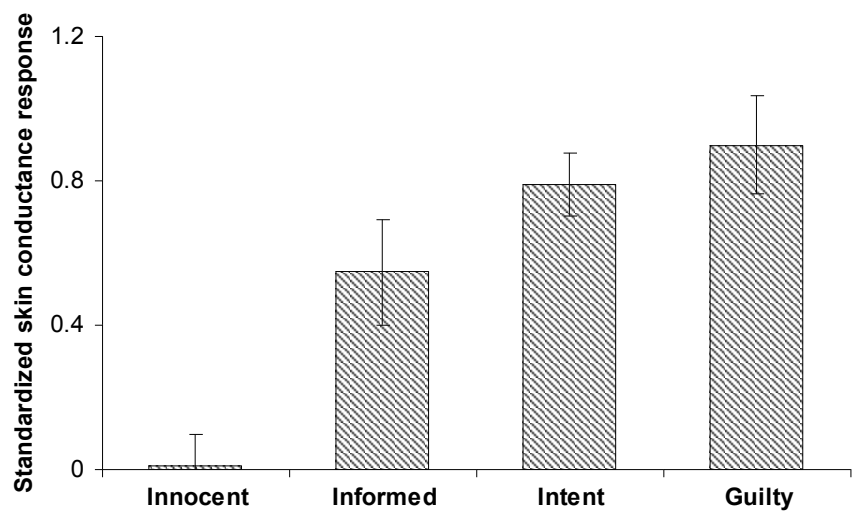

Fig. (1). Mean standardized skin conductance response to the four conditions. Error bars represent \pm 1 standard error of the mean.

Table 1. p-Values (Cohen's $d$ ) for the Post Hoc Comparison of the Four Conditions

\begin{tabular}{|c|c|c|c|}
\hline \multicolumn{4}{|c|}{ Condition } \\
\hline & Informed & Intent & Guilty \\
\hline \hline Innocent & $.004(0.97)$ & $<.001(1.52)$ & $<.001(1.69)$ \\
\hline Informed & & $.177(0.38)$ & $.054(0.55)$ \\
\hline Intent & & & $.538(0.18)$ \\
\hline
\end{tabular}

\section{DISCUSSION}

We investigated whether criminal intentions are detectable with the CIT. Results of our mock crime study show that a CIT procedure can indeed be used to detect intent. This suggests that the CIT can be used within the recent legal framework that requires procedures allowing for the detection of criminal intent.

The linear trend in CIT detection efficiency between the informed innocent, intent, and guilty condition was marginally significant. Although this trend may be partially explained by the lower recall rate in the informed condition, it is perfectly in line with orienting theory. Orienting theory states that the orienting response increases with increased stimulus significance. With an increased level of involvement, significance of the relevant stimuli is likely to increase, causing the linear trend that is present in our data. Interestingly, the difference between the informed and the guilty condition approached significance. This is consistent with studies showing that informed, but innocent participants show larger differential responding to correct and incorrect answer options than innocent participants, but less differential responding than guilty suspects (Ben-Shakhar, 1999; Bradley, 1996).

The finding that the CIT can detect intentions suggests that it may be used as a forensic tool in preventing crime. The present study can best be viewed as a laboratory analogue of a situation where the plan is already known to the investigative authorities, and potential suspects can be identified. Importantly, the CIT can also be used when the correct alternative is unknown to the investigative authorities. Under these circumstances, the answer option that systematically evokes the largest response is likely to be the correct answer, and warrants further investigation (Raskin, 1989). This approach is typically restricted to locating physical evidence, such as the body of a murder victim (Nakayama, 2002). However, given that the CIT can be used to detect intent, this yields an additional opportunity to prevent crimes, by disclosing intentions that were previously unknown to the investigative authorities (see also Meijer, Smulders, \& Merckelbach, in press).

A limitation of the current study is that participants were instructed to commit an illegal act or were informed about its details. That is, participants did not choose to commit an illegal act, nor did they voluntarily seek information about it. This has, of course to do with artificial nature of mock crime studies. One way to circumvent this problem is to conduct studies in which participants can choose to commit a crime or to inform themselves about it, rather than randomly appointing them to conditions.

Finally, two words of caution are in order. First, the informed and intent group did not differ from each other. This means that a positive CIT outcome should only be interpreted if the possibility that the suspect has gained knowledge about the crime other than through involvement can be excluded. Second, it is important to realize that the CIT format requires a limited number of answer alternatives per question. This requirement may limit the practical applicability of the test. In any case it needs to be used alongside good police investigations, as this may help to limit the number of plausible alternatives. When the latter can be achieved, the CIT can be used successfully to determine criminal involvement, regardless of whether that refers to crimes that have been committed or crimes that one intends to commit.

\section{REFERENCES}

Ben-Shakhar, G. (1985). Standardization within individuals: A simple method to neutralize individual differences in skin conductance. Psychophysiology, 22, 292-299.

Ben-Shakhar, G., \& Elaad, E. (2003). The validity of psychophysiological detection of information with the Guilty Knowledge Test: A metaanalytic review. Journal of Applied Psychology, 88, 131-151.

Ben-Shakhar, G., Gronau, N., \& Elaad, E. (1999). Leakage of relevant information to innocent examinees in the GKT: An attempt to reduce false-positive outcomes by introducing target stimuli. Journal of Applied Psychology, 84, 651-660.

Bradley, M. T., MacLaren, V. V., \& Carle, S. B. (1996). Deception and nondeception in guilty knowledge and guilty actions polygraph tests. Journal of Applied Psychology, 81, 153-160.

Hira, S., \& Furumitsu, I. (2002). Polygraphic examinations in Japan: Application of the guilty knowledge test in forensic investigations. International Journal of Police Science \& Management, 4, 16-27.

Lykken, D. T. (1959). The GSR in the detection of guilt. Journal of Applied Psychology, 43, 385-388.

Lykken, D. T. (1998). A tremor in the blood. New York: Plenum Press.

Lynn, R. (1966). Attention, Arousal and the Orienting Reaction. New York: Pergamon.

Meegan, D. V. (2008). Neuroimaging techniques for memory detection: Scientific, ethical, and legal issues. American Journal of Bioethics, 8, 9-20.

Meijer, E. H., Smulders, F. T. Y., Johnston, J. E., \& Merckelbach, H. L. G. J. (2007). Combining skin conductance and forced choice in the detection of deception. Psychophysiology, 44, 814-822.

Meijer, E. H., Smulders, F. T. Y., \& Merckelbach, H. L. G. J. (in press). Extracting concealed information from groups. Journal of Forensic Sciences. 
Merckelbach, H. L. G. J., \& Meijer, E. H. (2004). De geheugendetector. Mogelijkheden en beperkingen. Justitiële Verkenningen, 30, 62-78.

Nakayama, M. (2002). Practical use of the concealed information test for criminal investigation in Japan. In Kleiner, M. (Ed.). Handbook of polygraph testing. (pp. 49-86). San Diego, CA: Academic Press.

Raskin, D. C. (1989). Polygraph techniques for the detection of deception. In Raskin, D. C. (Ed.), Psychological Methods in Criminal Investigation and Evidence (pp. 247-296). New York: Springer.
Sokolov, E. N. (1963). Perception and the conditioned reflex. Oxford: Pergamon.

Verschuere, B., Crombez, G., De Clercq, A., \& Koster, E. H. (2004) Autonomic and behavioral responding to concealed information: differentiating orienting and defensive responses. Psychophysiology, 41, 461-466.

(C) Meijer et al.; Licensee Bentham Open.

This is an open access article licensed under the terms of the Creative Commons Attribution Non-Commercial License (http://creativecommons.org/licenses/by$\mathrm{nc} / 3.0 /$ ) which permits unrestricted, non-commercial use, distribution and reproduction in any medium, provided the work is properly cited. 